\title{
Development of Fire and Explosion Risk Assessment on Coal Reclaim Tunnel Using Monte Carlo Simulation and Risk Matrix Method
}

\author{
Nuhindro Priagung Widodo ${ }^{1}$, Dimas Agung Permadi ${ }^{1}$, Ahmad Ihsan ${ }^{1}$, and Ginting Jalu \\ Kusuma $^{1}$ \\ ${ }^{1}$ Institut Teknologi Bandung
}

July 7, 2021

\begin{abstract}
The comprehensive fire and explosion risk assessment has been studied for Coal Reclaim Tunnel (CRT) facility by applying the Monte Carlo simulation method. In this research, the fire and explosion risk of two existing CRT, namely model A and model $\mathrm{B}$, have been assessed. A set of 30 data for each factor has been used to define the statistical distribution model, sourced from historical data, field measurement, and laboratory experiments. Based on the simulation, CRT model A has a 100\% extreme risk group, while model $\mathrm{B}$ has two risk groups, high risk $=81.73 \%$ and moderate risk $=18.27 \%$, classified as a not acceptable risk. Several preventive actions were set to reduce the probability and severity level as low as reasonably possible, especially for the controllable factors. Furthermore, the probability and severity levels were re-adjusted by the Monte Carlo simulation. The result shows that both the CRT model have been grouped into a 100\% moderate-risk group. For optimal prevention against explosion risk, a sensitivity analysis has been carried out to find the most influential factors for the fire and explosion risk in CRT. Through this research, a method for risk matrix assessment related to the fire and explosion in the CRT facility has been developed.
\end{abstract}

\section{Hosted file}

Manuscript_Risk Assessment Coal Reclaim Tunnel_submit.docx available at https://authorea.com/ users/424295/articles/529411-development-of-fire-and-explosion-risk-assessment-on-coalreclaim-tunnel-using-monte-carlo-simulation-and-risk-matrix-method 